\title{
Criando laços: a gestão da comunicação e da educação em instituições de ensino privadas
}

Leda Márcia Arashiro

Especialista em Gestão da Comunicação pela

Escola de Comunicações e Artes da USP

E-mail: ledamarcia@gmail.com

Resumo: Os processos de comunicação estão presentes em todas as organizações. Nas instituições de ensino, em particular, eles deveriam ser fluentes, dialógicos e integrados, e seu planejamento deveria ser complementar à proposta pedagógica, pois processos adequados de comunicação em ambientes educacionais refletem uma melhor organização das atividades, com conseqüente progresso no aproveitamento dos alunos. Porém, constatamos que, em geral, as instituições de ensino, especialmente as privadas, tendem a ter processos de comunicação hierarquizados, que dificultam que o processo flua entre departamentos, funcionários, docentes, alunos e seus familiares. A interação entre a Comunicação Social e a Educação pode criar propostas de trabalho que propiciem a implementação de processos de comunicação saudáveis e que visualizem a comunicação de forma abrangente. Uma destas propostas é a organização de um memorial escolar como ponto de partida para a formação de um verdadeiro ecossistema comunicativo na escola.

Palavras-chave: educomunicação, Gestão da Comunicação, Educação, memória.
Abstract: The communication processes are in all the organizations. In the Institutions of Education, in particular, them they would have fluent and to be integrated, and the planning of the communication would have to be to complement to the proposal pedagogical, therefore an adequate planning of the processes of communication in educational environments reflects in one better organization of the activities, with consequent improvement of the exploitation of the students. However, in general, the private Institutions of Education tend to have hierarchical processes of communication, that they make the process doesn't flow between departments, employees, teachers, students and their parents. The interaction between Communication and Education can create work proposals that propitiate a healthful processe of communication. One of these proposals is the organization of a school memorial as starting point for the formation of a healthful of communication in the school.

Keywords: educommunication, Communication management, Education, memory.

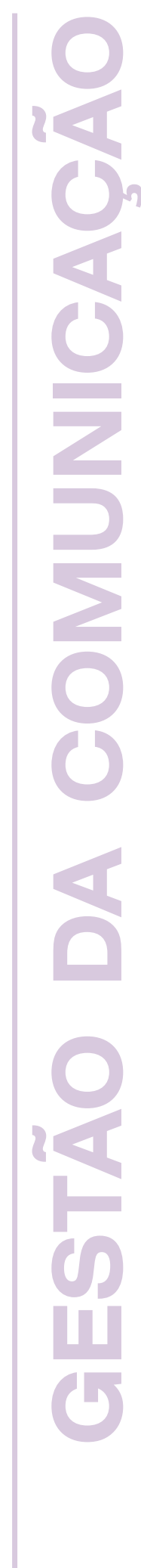

Recebido: 18/02/2008

Aprovado: 03/03/2008 
1. Título obtido através do Curso de Especialização Lato Sensu Gestão da Comunicação, da ECAUSP, em 2007.

2. Para garantir a fidedignidade das informações, comprometemo-nos junto às instituições de ensino pesquisadas a conserválas no anonimato, bem como as pessoas entrevistadas para o projeto.

3. Ecossistema comunicativo é o conceito utilizado por diversos autores, entre eles Jesús Martín-Barbero, designando uma comunicação integrada entre projeto pedagógico, professores, alunos, público externo e comunidade como um todo. $\mathrm{O}$ conceito será mais bem definido ao longo do texto.

4. Sobre esta representação dos gráficos, ver: LAET, Maria Aparecida. Gestão do conhecimento e comunicação: o fluxo do conhecimento dentro das empresas. Trabalho de Conclusão de Curso. Gestão de Processos Comunicacionais. Escola de Comunicações e Artes. Universidade de São Paulo. 2003. comunicação \& educação • Ano XIII • Número 2 • maio/ago 2008

Este projeto de intervenção foi elaborado para obtenção do título de Especialista em Gestão da Comunicação, pela Escola de Comunicações e Artes da Universidade de São Paulo - USP ${ }^{1}$. O objeto de estudo é uma instituição de ensino privada paulistana ${ }^{2}$, composta por duas faculdades e dois colégios. As faculdades ministram cursos nas áreas de Informática e Administração de Empresas. Os colégios oferecem cursos do Ensino Fundamental, Ensino Médio e Cursos Técnicos em Informática e Administração de Empresas.

Essa estrutura complexa é resultado da expansão do que foi inicialmente um colégio de primeiro grau que buscou atender a demandas emergentes da região e da cidade. $\mathrm{O}$ resultado foi uma teia organizacional complexa e não planejada com grandes problemas no fluxo de comunicação entre as partes funcionários, escolas e departamentos -, fragmentando o processo de comunicação em todas as suas instâncias.

Depois de pesquisa empírica e bibliográfica, foi elaborado o projeto de um Memorial, recuperando a história da instituição e de seu processo de crescimento, resultante da participação efetiva de todos aqueles que mantiveram algum tipo de vínculo com as escolas do grupo educacional analisado. A constituição do Memorial é vista como o ponto de partida para a criação de um espaço que possibilite a troca de informações entre todos.

O processo de organização e realização do Memorial poderá trazer, se bem conduzido, a constituição de um ecossistema comunicativo saudável ${ }^{3}$. Partiremos de um processo coletivo de discussão e de outros recursos de troca e interatividade que garantam a participação e o envolvimento de representantes de todos os níveis funcionais e de todos os departamentos no processo. As bases teóricas que nos ajudaram a conceituar a pesquisa são os conceitos de Educomunicação, um campo de intervenção social que inter-relaciona a Comunicação Social e a Educação, com a utilização dos recursos da Comunicação para potencializar o aprendizado, e seus conceitos, como o ecossistema comunicativo articulado por Jesús Martín-Barbero.

\section{INICIANDO A PESQUISA}

$\mathrm{O}$ interesse em elaborar este projeto veio do fato de trabalharmos nesta instituição de ensino como coordenadora do Departamento de Comunicação. Para entender melhor a organização, procuramos saber como se processava o fluxo de comunicação. Para tanto, foram realizadas 18 entrevistas em profundidade com funcionários, diretores e coordenadores das escolas e funcionários administrativos da entidade mantenedora, mapeando seus fluxos comunicacionais. O resultado levou-nos a perceber a fragmentação e o isolamento existente entre departamentos, instâncias e funcionários da organização. Para melhor explicitarmos essa etapa da pesquisa, elaboramos gráficos, como o que exibimos a seguir4. 
Criando laços - Leda Márcia Arashiro

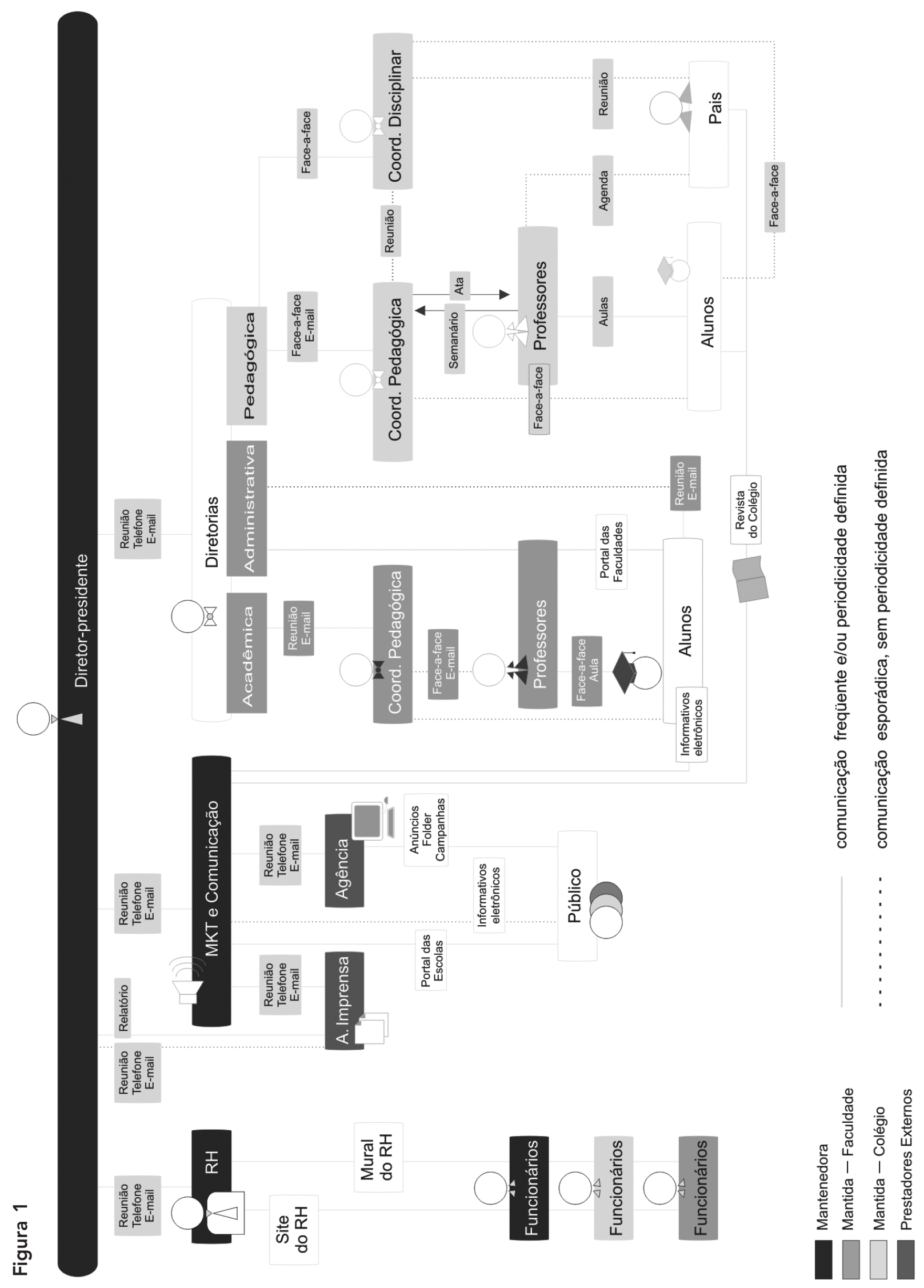


Observa-se na figura 1 que os processos de comunicação desta instituição de ensino são unidirecionais e hierarquizados, com pouco fluxo de comunicação entre pais, alunos e professores com a cúpula. $\mathrm{O}$ mesmo se dá com a relação entre funcionários, departamento de Recursos Humanos e a alta administração. São escassos os meios de comunicação que permitam que a mensagem flua entre os departamentos, escolas e funcionários. Grandes vazios e espaços de silêncio aparecem onde deveria haver comunicação, interação e diálogo.

\section{METODOLOGIA DE PESQUISA}

Para propor um projeto de intervenção capaz de desfazer as barreiras existentes entre os diferentes grupos e estratos da instituição, partimos de algumas hipóteses:

1. A comunicação em ambientes educacionais deve ser fluente, dialógica e integrada.

2. O planejamento da comunicação deve ser complementar à proposta pedagógica.

3. O planejamento adequado de comunicação refletirá na melhor organização das atividades, com conseqüente melhoria do aproveitamento dos alunos.

A metodologia de pesquisa compreendeu, além de novas entrevistas com os profissionais da instituição, entrevistas com coordenadores de comunicação de quatro instituições de ensino privadas que tivessem uma história de crescimento e uma atuação semelhante ao grupo estudado. Através dessas entrevistas, pudemos mapear o processo de comunicação nessas outras instituições, gerando gráficos semelhantes ao que já apresentamos para nossos leitores. Os resultados obtidos serão apresentados sob forma de descrição comentada, a partir de análise de conteúdo das entrevistas.

\section{INSTITUIÇÃO DE ENSINO 2}

A instituição de ensino 2 é um grupo educacional de grande porte. Possui oito campi, oferece 33 cursos de graduação e nove de pós-graduação, e conta com mais de 10 mil alunos, sendo 9,5 mil na universidade e 1,3 mil nos colégios.

Observa-se na figura 2 que os processos de comunicação da instituição são também unidirecionais, havendo pouca troca de informações entre funcionários, docentes, alunos e familiares de alunos. Há uma troca maior de informações somente entre o reitor, os diretores e os coordenadores pedagógicos.

Nota-se que os processos de comunicação são hierarquizados, pois os alunos e familiares mantêm contato freqüente somente com professores, que por sua vez contatam seus respectivos coordenadores. O reitor e os diretores comunicam-se com os professores, alunos e seus familiares somente por intermédio do jornal mensal da instituição. 
Criando laços • Leda Márcia Arashiro

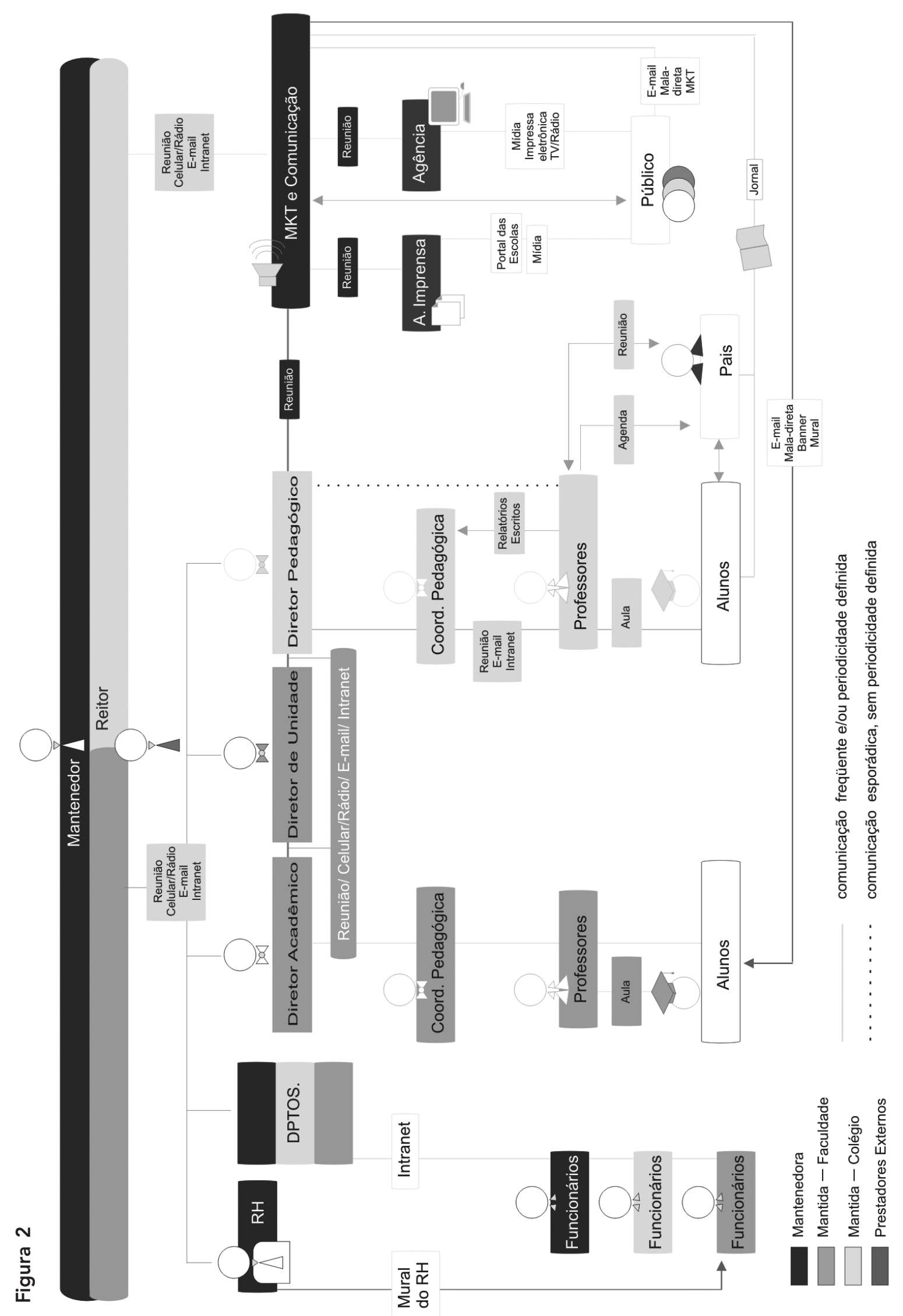


comunicação \& educação • Ano XIII • Número 2 - maio/ago 2008

\section{INSTITUIÇÃO DE ENSINO 3}

A instituição de ensino 3 oferece sete cursos de graduação na metodologia de ensino a distância (EAD) e conta com cerca de 300 alunos. O Ensino Fundamental e Médio - que são oferecidos na modalidade presencial - atendem a 840 alunos.

Observa-se na figura 3 que os processos de comunicação são centralizados na gerente administrativa. Apesar de hierarquizado, o fluxo de comunicação permite o contato de pais e professores com a cúpula em determinados momentos, como nas palestras mensais que o colégio promove para pais e familiares.

Para comunicar-se com os pais de alunos, a escola utiliza agendas que transitam da instituição para as residências, o envio de documentos pelo correio, ou o telefone. Outra forma de comunicação usada é o boletim informativo, publicado para cada ciclo, orientando sobre eventos e atividades estudantis.

O contato dos professores com os coordenadores e a direção do colégio é diário no Ensino Fundamental e Médio. Na faculdade, os coordenadores pedagógicos ficam fisicamente isolados, comunicando-se por telefone ou e-mail.

\section{INSTITUIÇÃO DE ENSINO 4}

A instituição de ensino 4 é administrada por uma entidade religiosa. O colégio atende cerca de 3 mil alunos e oferece os cursos de Ensino Infantil até Ensino Médio. A faculdade dispõe de quatro cursos de graduação e cinco cursos de pós-graduação.

Observa-se na figura 4 que os processos de comunicação estão centralizados no Departamento de Comunicação, que responde tanto à entidade mantenedora quando realiza os trabalhos de marketing, assessoria de imprensa e comunicação interna - quanto ao colégio, quando ministra cursos de capacitação aos alunos para editar programas de rádio ou para elaborar textos para a revista da escola. O Departamento de Comunicação também é o responsável pela capacitação dos alunos na realização de vídeos.

Uma vez por ano, o colégio organiza um festival de cinema aberto à comunidade, com a apresentação de todos os vídeos produzidos pelos alunos. Nesses eventos, os pais costumam trocar idéias com os professores e coordenadores do colégio.

Os funcionários, professores, diretores e coordenadores do colégio não mantêm nenhum tipo de comunicação com a faculdade. Apesar de serem hierarquicamente ligados à mesma reitoria, eles se consideram integrantes de grupos diferentes.

O processo de comunicação é hierarquizado, constituindo o reitor a autoridade máxima da instituição de ensino. 


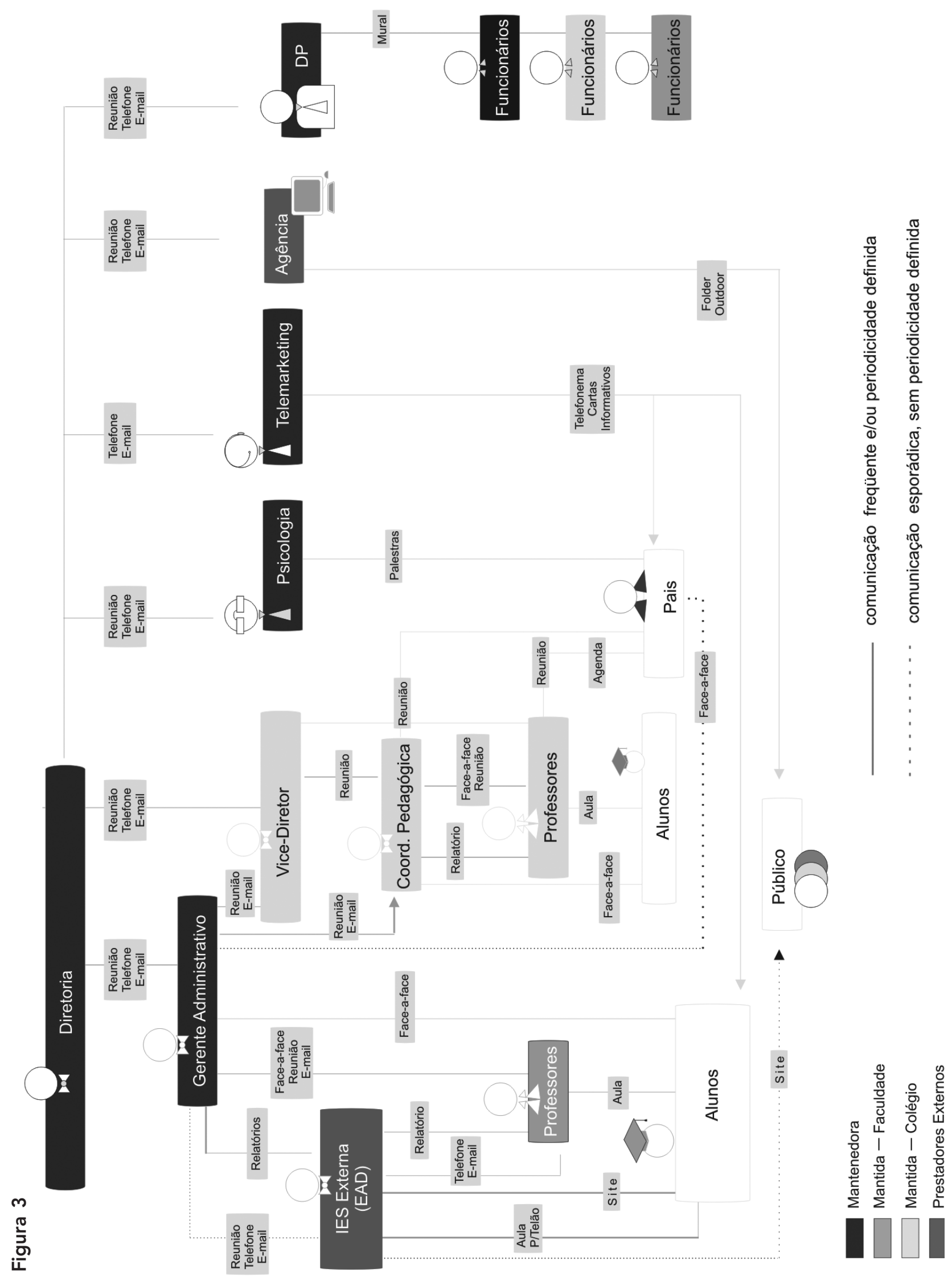


comunicação \& educação • Ano XIII • Número 2 • maio/ago 2008

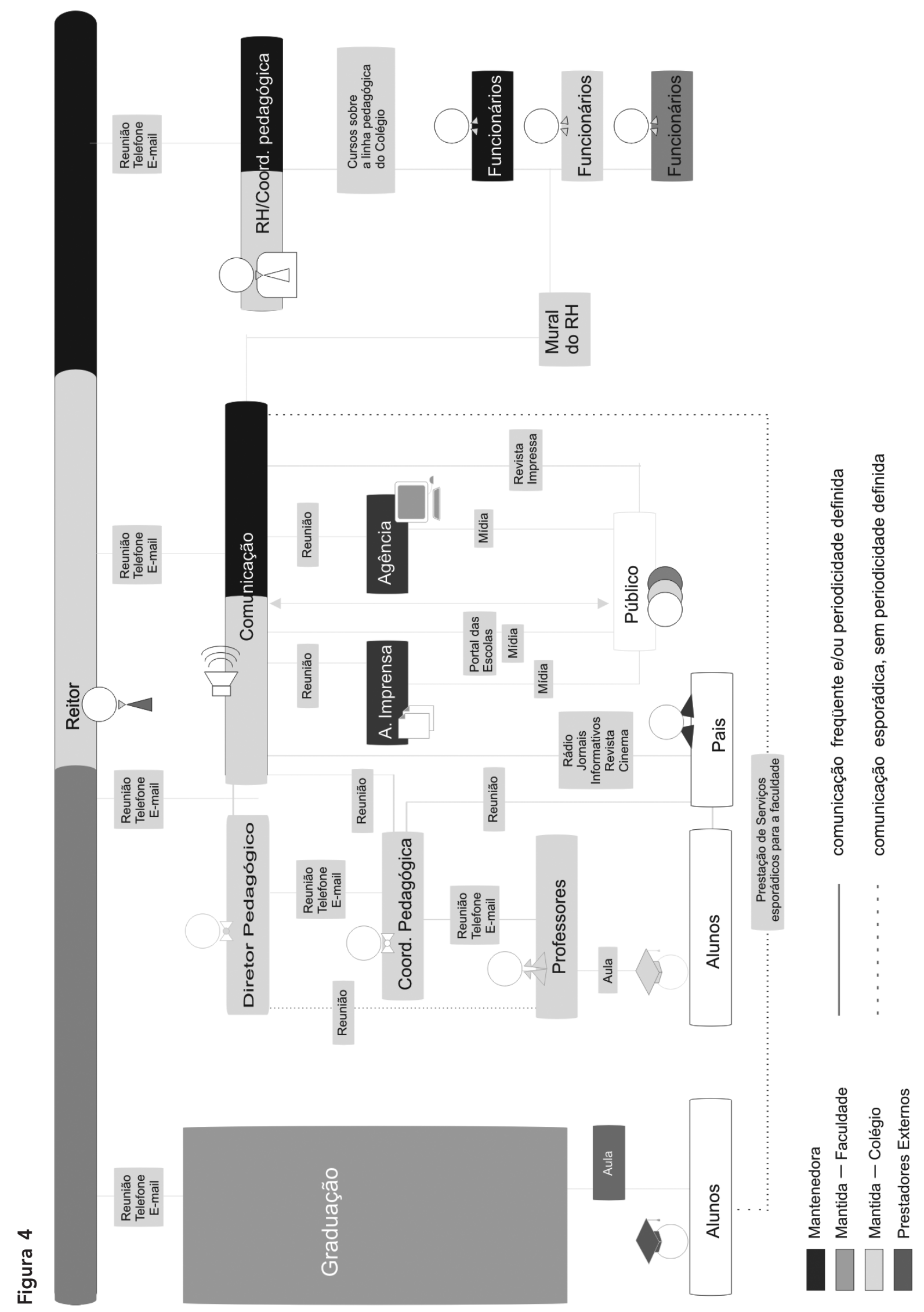




\section{INSTITUIÇÃO DE ENSINO 5}

A instituição de ensino 5 é administrada por uma fundação. Trabalha com 5.300 alunos e 430 professores. O colégio conta com duas unidades que oferecem os cursos de Educação Infantil, Ensino Fundamental e Ensino Médio. A faculdade dispõe de 13 cursos de graduação, 12 de extensão e 10 de pós-graduação.

Observa-se na figura 5 que o fluxo de informação é hierarquizado, verticalizado, com as informações concentrando-se no diretor-geral da faculdade, no superintendente da entidade mantenedora e no presidente, sendo raras as oportunidades de comunicação dos coordenadores, professores, supervisores, pais e alunos com o alto escalão.

Os processos de comunicação da instituição de ensino 5 não contemplam fluxos de comunicação entre os docentes de ciclos diferentes, fragmentando o processo. As salas dos professores são separadas de acordo com os ciclos, o que dificulta a comunicação entre eles.

Apesar dos processos de comunicação hierarquizados e fragmentados, existem algumas brechas que permitem o processo de comunicação fluir entre os funcionários: são os comitês formados para organização de eventos, que parecem funcionar como um ponto de encontro em que os funcionários podem se conhecer e trocar idéias não só a respeito do planejamento do evento que deu origem à formação do comitê, mas sobre qualquer assunto.

As ferramentas de comunicação da escola com os familiares dos alunos da Educação Infantil e do Ensino Fundamental I resumem-se a uma agenda e uma pasta em que os professores colocam as circulares do colégio.

\section{ANÁLISE GERAL}

Apesar de os eventos rotineiros objetivarem a aproximação de alunos e familiares com as escolas, os processos de comunicação das instituições de ensino pesquisadas são centralizados, havendo pouca troca de informação entre funcionários e docentes, docentes e familiares de alunos, docentes e alta administração.

Uma característica comum é a hierarquia, que controla o diálogo e as informações que circulam no ambiente escolar, prejudicando o processo de comunicação e não permitindo - de maneira geral - sua fluidez.

Apesar de existirem algumas aberturas que permitem a melhoria do processo de comunicação entre as pessoas que fazem parte das instituições pesquisadas, estamos distantes de um ecossistema comunicativo saudável, que pensa a comunicação como um todo, de forma abrangente, sem as divisões convencionais em comunicação interna e externa, institucional e pública. 
comunicação \& educação • Ano XIII • Número 2 • maio/ago 2008

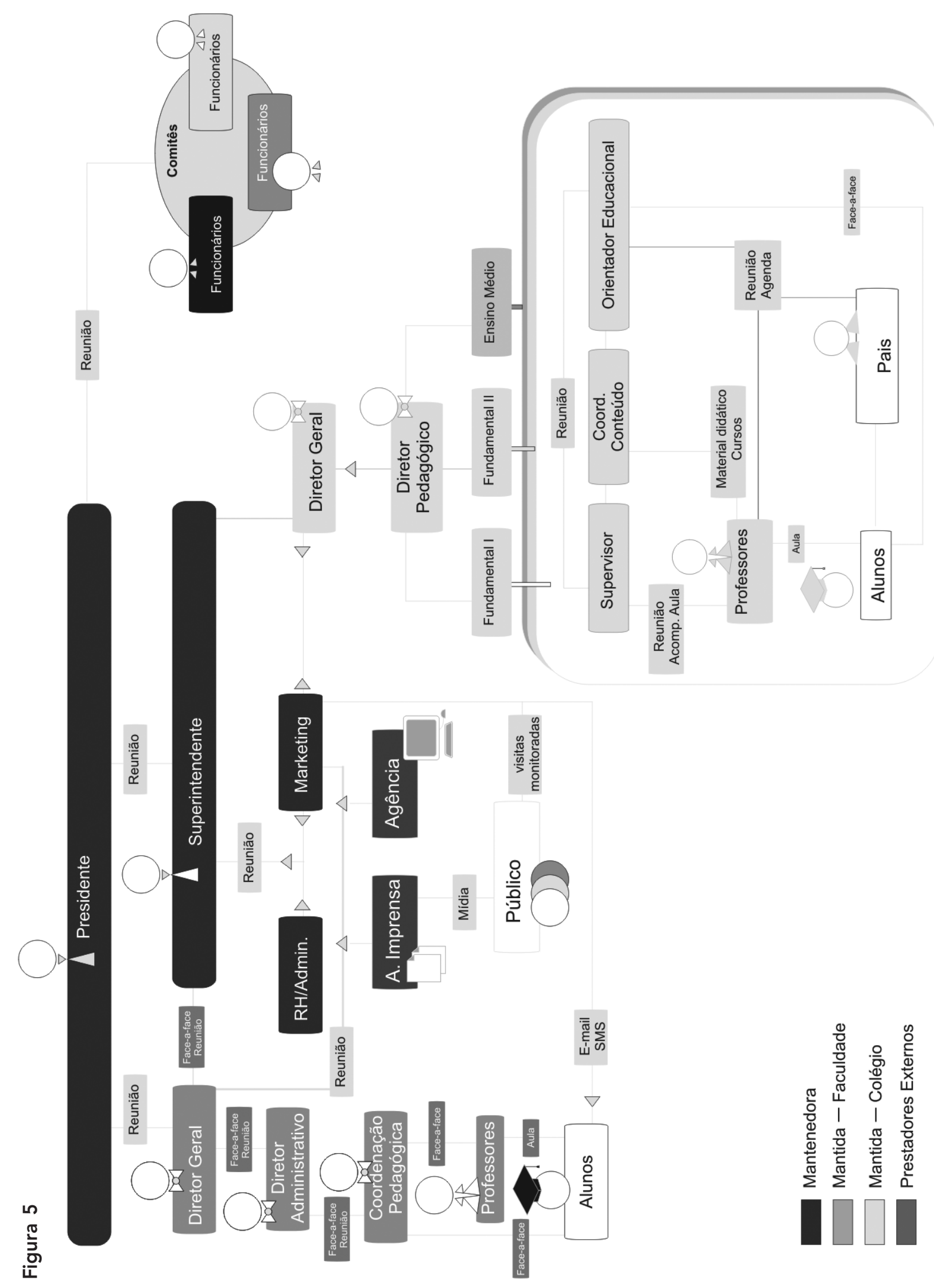




\section{A EDUCAÇÃO E A COMUNICAÇÃO - FERRAMENTAS DO GESTOR DA COMUNICAÇÃO}

Nos últimos anos, os meios de comunicação vêm se impondo como uma realidade muito forte, presente e significativa no cotidiano das pessoas. Não se pode ignorar a influência dos meios de comunicação no processo de aprendizagem, sendo responsáveis por grande parte do conhecimento adquirido pelas pessoas atualmente.

Tal fato passou a chamar a atenção de pesquisadores da Comunicação, que têm buscado na Educação aportes teóricos que possam indicar caminhos para a sociedade desenvolver uma maneira de olhar mais crítica em relação a esse mar de informações despejado pelos meios. Um destes caminhos é a chamada Educomunicação, um campo de intervenção social que inter-relaciona a Comunicação Social e a Educação, com a utilização dos recursos da Comunicação para potencializar o aprendizado ${ }^{5}$. Costa afirma que as razões para que essa integração se observe, tanto na academia quanto na prática, "são, principalmente, de natureza social - a crise se avizinha desses campos do conhecimento e exige a busca de novos procedimentos e novos modelos de explicação da realidade" ${ }^{6}$.

A Educomunicação, portanto, define-se como um conjunto de ações destinadas a: observar como os meios de comunicação agem na sociedade e a buscar formas de conviver com eles sem se deixar manipular; rever as relações de comunicação no ambiente em que se estuda ou se trabalha para criar espaços abertos e democráticos; facilitar o processo de aprendizagem e oferecer recursos para que todos possam expressar-se ${ }^{7}$.

Para Soares:

[...] o locus de ação da Educomunicação são os ecossistemas comunicativos, ambos intrinsecamente ligados, já que a primeira é representada pelo conjunto de ações que permitem que educadores, comunicadores e outros agentes promovam e ampliem as relações de comunicação entre as pessoas que compõem a comunidade educativa. Do conceito de ecossistema desenvolvido pela Biologia, é importante ressaltar a relação de trocas, de interdependência entre seres diferentes, que acontece em variados níveis; e do fato de que ecossistemas maiores podem conter ecossistemas menores ${ }^{8}$.

O conceito de ecossistema comunicativo foi articulado por Jesús MartínBarbero, "não apenas conformado pelas tecnologias e meios de comunicação, mas também pela trama de configurações constituída pelo conjunto de linguagens, representações e narrativas que penetra nossa vida cotidiana de modo transversal" 9 .

Para Soares, verdadeiros ecossistemas comunicativos cuidam "da saúde e do bom fluxo das relações entre as pessoas e os grupos humanos, bem como do acesso de todos ao uso adequado das tecnologias da informação" ${ }^{\text {. }}$.

Com a Educomunicação é possível buscar-se a democratização da ação comunicativa para que o processo de comunicação alcance a eficiência e a eficácia que se espera, visando
5. SOARES, Ismar de Oliveira. Comunicação/ Educação: a emergência de um novo campo e o perfil de seus profissionais. Contato, Brasília: Senado Federal, v. 1, n. 2, p. 19, jan./mar. 1999.

6. COSTA, Maria Cristina Castilho. Educomunicador é preciso! Disponível em: <http://www.jornalescolar.org.br/site/1376/ nota/18222>. Acesso em: 30 out. 2007.

7. Anotações de aula. Ismar de Oliveira Soares. Curso de pós-graduação lato sensu Gestão da Comunicação. Escola de Comunicações e Artes da Universidade de São Paulo. 30 mar. 2007.

8. SOARES, Ismar et al. O Projeto Educom.TV: formação online de professores numa perspectiva educomunicativa. Revista Digital de Tecnologia Educacional e Educação a Distância, v. 1, n. 1, nov. 2004. Disponível em: <http://www.pucsp. $\mathrm{br} / \mathrm{tead} / \mathrm{n} 1 \mathrm{a} /$ artigos2/resumo2.htm>. Acesso em: 29 out. 2007.

9. Ibid.

10. Ibid. 
comunicação \& educação • Ano XIII • Número 2 - maio/ago 2008

[...] garantir, mediante o compromisso e a criatividade de todos os envolvidos e sob a liderança de profissionais qualificados, o uso adequado dos recursos tecnológicos e o exercício pleno da comunicação entre as pessoas que constituem a comunidade, assim como entre esta e os demais setores da sociedade ${ }^{11}$.

Portanto, a Educomunicação parece ser o caminho para modificarem-se cenários onde predominam os modelos funcionalistas de comunicação, em que é preciso implementar processos que considerem a comunicação como um todo e permitam que a mensagem flua de forma multidirecional, ampliando a capacidade de expressão de todos os membros de uma organização.

O gestor responsável pela implementação desses processos de comunicação precisará estar atento ao novo pacto social em torno do problema da produção e do uso dos meios, que privilegie

[...] o uso dos processos, recursos e tecnologias da informação a partir da perspectiva de uma mediação participativa e democrática da comunicação. Isto inclui tanto o desenvolvimento e o emprego das tecnologias para a otimização das práticas educativas quanto a capacitação dos educandos para o seu manejo, assim como a recepção organizada, ativa e crítica das mensagens massivas ${ }^{12}$.

Dessa forma, o gestor da comunicação vai se transformar em gestor educomunicativo. Contribuirá para a alteração do processo de comunicação organizacional em educomunicativo, com atividades destinadas à manutenção do ecossistema comunicativo da instituição, em que deve haver um verdadeiro diálogo comunicativo que possibilitará a continuidade da saúde empresarial, por meio de canais limpos e saudáveis de comunicação entre todos os atores que fazem parte deste intrincado roteiro organizacional.

Porém, para o estabelecimento de um verdadeiro ecossistema comunicativo nas instituições de ensino focalizadas no projeto de intervenção, será preciso elaborar um planejamento eficiente, que englobe todas as oportunidades existentes que permitam o alargamento dos debates e das discussões para o desenvolvimento saudável da formação de opinião entre todos. Este processo terá que ser implementado com o aproveitamento de lacunas, a fim de modificar paulatinamente o controle hegemônico do processo de comunicação exercido pela classe dirigente, sem ferir a cultura organizacional vigente para que não haja rejeição à implementação do projeto de intervenção.

\section{PROJETO DE INTERVENÇÃO}

Este projeto de intervenção começou a delinear-se no momento em que

11. SOARES, Comunicação/Educação, op. cit., p. 41.

12. Ibid. neçamos a realizar as primeiras entrevistas com os funcionários mais antigos da instituição de ensino 1, quando muitos se emocionaram ao relembrar as histórias das escolas. Foi interessante notar o carinho com que muitos se referiam ao fundador e o incentivo da maioria das pessoas para que continuássemos o trabalho de resgate da história da instituição. 
Todos os depoimentos contribuíram para nos indicar que seria possível trilhar um caminho, embasado na Educomunicação, que pudesse ajudar a resolver o problema comunicacional detectado neste trabalho.

A inspiração para esse caminho veio da leitura do livro Memória e cultura: a importância da memória na formação cultural humana, organizado por Danilo Santos de Miranda. A obra reúne as conferências, os debates e os relatos de experiências apresentados em setembro de 2006, no Seminário Internacional Memória e Cultura: a importância da memória na formação cultural, organizado pelo SESC de São Paulo para promover "o debate e a difusão de experiências desenvolvidas em núcleos de preservação da memória, localizados em instituições culturais, universidades, empresas, comunidades e organizações afins"13.

O contato com as diversas experiências relatadas na obra levou a pesquisadora a refletir sobre o fato de que a organização de um memorial escolar, com a efetiva participação de todos que mantêm ou mantiveram algum tipo de vínculo com a instituição de ensino 1 em algum momento de sua vida, poderia ser o ponto de partida para a conquista de um espaço que possibilite a troca de informações entre todos. O próprio processo de organização e construção do memorial poderia trazer, se bem conduzido, a construção de um ecossistema comunicativo saudável, pois, segundo Alvisi, "o ato de recuperar a memória de forma compartilhada é um trabalho que constrói sólidas pontes de relacionamento entre os indivíduos"14.

Dessa forma, o que este trabalho propõe como projeto de intervenção é a organização de um memorial escolar com a participação efetiva de todos aqueles que mantiveram algum tipo de vínculo com as escolas deste grupo educacional. Deseja-se que o trabalho se transforme num processo que permita o aumento dos debates e das discussões que possibilitem o desenvolvimento saudável da formação de opinião entre todos, implementando um verdadeiro ecossistema comunicativo na instituição de ensino 1.

Partimos do pressuposto de que esse projeto terá que passar por um processo coletivo de discussão, sendo que sua organização e posterior implementação serão viáveis somente com a participação e o envolvimento de representantes de todos os níveis e departamentos no processo.

É importante frisar que este projeto não deverá se restringir a uma simples exposição dos objetos históricos ou do acervo documental a serem angariados para o memorial escolar. Indo muito além, deverá incluir em seu escopo a capacitação dos componentes do grupo na sua organização, manutenção e divulgação. Pretende, ainda, proporcionar aos participantes o exercício da mediação tecnológica através do computador, da comunicação em rede e da construção do conhecimento, e familiarizá-los com as novas tecnologias de comunicação, transformando o projeto de organização do memorial escolar em um projeto educomunicativo.

Um dos primeiros passos a empreender será motivar as pessoas a participar do projeto. Para tanto, vamos propor sua divulgação nos veículos de comunicação utilizados atualmente pela instituição de ensino 1, além de divulgá-lo nos
13. MIRANDA, Danilo Santos de (Org.). Memória e cultura: a importância da memória na formação cultural humana. São Paulo: Edições SESC-SP, 2007. p. 8.

14. ALVISI, Lílian de Cássia. A recuperação da memória escolar: uma estratégia político-educacional. Memorial escolar em Poços de Caldas (MG). In: MIRANDA, op. cit., p. 258. 
* Sobre a ferramenta Wiki, ver: GOMES, Mayra Rodrigues. A ferramenta wiki: uma experiência pedagógica. Comunicação \& Educação, São Paulo: CCA-ECA-USP/Paulinas, ano XII, n. 2, maio/ago. 2007. (N.E.)

15. Para mais informações sobre produções colaborativas na internet ver ARASHIRO, Leda M. Jornalismo colaborativo: a participação das fontes na produção da notícia. Monografia (Graduação em Comunicação Social)Faculdades Integradas Rio Branco. São Paulo, 2005. jornais de bairro e nas reuniões de professores que acontecem no início do semestre letivo para todos os ciclos.

Será proposto aos alunos e professores das faculdades que elaborem um projeto para construção de um ambiente virtual que permita a participação interativa de todos os componentes do grupo. Vamos sugerir que esse ambiente também possa funcionar como um memorial escolar virtual, com salas virtuais para exposição dos materiais fotografados e documentos escaneados, além de locais para armazenamento das histórias orais coletadas pelo grupo, por exemplo.

A partir das interações nesse ambiente virtual, passaremos para a criação de um jornal colaborativo virtual, com notícias sobre o andamento do projeto de organização do memorial escolar, no qual todos poderão expressar-se democraticamente. Para tanto, utilizaremos a ferramenta Wiki", um espaço colaborativo na internet que permite a edição coletiva dos documentos sem que haja necessidade de seu conteúdo ser aprovado antes de sua publicação. Esse tipo de espaço colaborativo é uma espécie de blog coletivo, no qual um site fornece uma área para publicação de relatos de experiências. Todos os componentes de um grupo podem inserir ou modificar textos, figuras, fotos ou ilustrações de forma coletiva, sem que haja um editor responsável pelos conteúdos ${ }^{15}$. Capacitaremos os componentes do grupo na utilização da ferramenta como instrumento de comunicação, procurando desenvolver um olhar crítico em relação à produção midiática, com discussões e análises sobre a mídia em geral. As bases teóricas serão debates sobre Educomunicação e seus conceitos, com apoio em textos e artigos do curso de Gestão de Processos Comunicacionais, da ECA/USP.

Incentivaremos o desenvolvimento de projetos interdisciplinares nesses espaços colaborativos, com a participação de todos os componentes do grupo na produção de reportagens e video-reportagens.

Aqueles que têm dificuldade em trabalhar com computadores serão incentivados a participar de cursos de capacitação, que poderão ser ministrados pelos próprios alunos nos laboratórios da escola.

Além da interação do grupo no ambiente virtual, este projeto pretende: manter encontros presenciais do grupo periodicamente, para estreitar vínculos pessoais e afetivos; aprofundar os debates realizados virtualmente; e propor atividades práticas sobre a organização e implementação do memorial escolar.

Ponto importante na condução deste projeto será a manutenção de um fluxo de comunicação intenso e dialogal entre todos os componentes do grupo, para estabelecer um ecossistema comunicativo saudável que possibilite a troca de informações, experiências e idéias. Assim, se bem conduzido, este projeto permitirá que o relacionamento educomunicativo construído durante sua implementação seja levado para as escolas da instituição de ensino 1, para modificar paulatinamente seu modelo funcionalista de comunicação. 


\section{REFERÊNCIAS BIBLIOGRÁFICAS}

ALVISI, Lílian de Cássia. A recuperação da memória escolar: uma estratégia político-educacional. Memorial escolar em Poços de Caldas (MG). In: MIRANDA, Danilo Santos de (Org.). Memória e cultura: a importância da memória na formação cultural humana. São Paulo: Edições SESC-SP, 2007.

ARASHIRO, Leda M. Jornalismo colaborativo: a participação das fontes na produção da notícia. Monografia (Graduação em Comunicação Social)-Faculdades Integradas Rio Branco. São Paulo, 2005.

COSTA, Maria Cristina Castilho. Educomunicador é preciso! Disponível em: <http://www.jornalescolar.org.br/site/1376/nota/18222>. Acesso em: 30 out. 2007.

GOMES, Mayra Rodrigues. A ferramenta wiki: uma experiência pedagógica. Comunicação \& Educação, São Paulo: CCA-ECA-USP/Paulinas, ano XII, n. 2, maio/ago. 2007.

LAET, Maria Aparecida. Gestão do conhecimento e comunicação: o fluxo do conhecimento dentro das empresas. Trabalho de Conclusão de Curso. Gestão de Processos Comunicacionais. Escola de Comunicações e Artes. Universidade de São Paulo. 2003.

MIRANDA, Danilo Santos de (Org.). Memória e cultura: a importância da memória na formação cultural humana. São Paulo: Edições SESC-SP, 2007.

SOARES, Ismar de Oliveira. Comunicação/Educação: a emergência de um novo campo e o perfil de seus profissionais. Contato, Brasília: Senado Federal, v. 1, n. 2, jan./mar. 1999 .

SOARES, Ismar et al. O Projeto Educom.TV: formação online de professores numa perspectiva educomunicativa. Revista Digital de Tecnologia Educacional e Educação a Distância, v. 1, n. 1, nov. 2004. Disponível em: <http://www.pucsp. br/tead/nla/artigos2/resumo2.htm>. Acesso em: 29 out. 2007. 